\title{
Evidenciação de responsabilildade social como ferramenta de sustentabilidade em fábrica de móveis do Vale do Caí - Rio Grande do Sul
}

Disclosure of social responsibility in a furniture factory in the Cai Valley - Rio Grande do Sul

\author{
Eduardo Selbach', Roberto Naime ${ }^{2}$
}

\author{
'Programa de pós-graduação em Qualidade Ambiental, Universidade Feevale, Novo Hamburgo,RS, Brasil \\ ${ }^{2}$ Professor do Programa de pós-graduação em Qualidade Ambiental, Universidade Feevale, Novo Hamburgo,RS, Brasil
}

\section{Resumo}

Este trabalho realiza os levantamentos das ações sistemáticas executadas por empresa fabricante de móveis no vale do Cai para incentivar e promover a participação dos colaboradores e da comunidade em que está inserida em ações de responsabilidade social. Estas iniciativas decorrem de demandas geradas pelas partes interessadas (stakeholders) e que a organização busca satisfazer e evidenciar da forma mais eficiente possível para cumprir suas funções sociais dentro das expectativas e percepções comunitárias, buscando qualificar seu ambiente de trabalho organizacional em busca de sustentabilidade geral e melhores condições de qualidade de vida para todos.

Palavras-chave:Estudo de caso. Indústria Moveleira. Diagnóstico de Responsabilidade social.

\begin{abstract}
This paper performs systematic surveys of the actions performed by the manufacturer of the furniture worth Cai to encourage and promote the participation of employees and the community in which it is embedded in social responsibility. These initiatives stem from demands generated by interested parties (stakeholders) and that the organization seeks to satisfy and highlight the most efficient way to fulfill their social roles within the community expectations and perceptions, seeking to qualify his organizational work environment in search of general sustainability and best conditions of quality of life for all.
\end{abstract}

Keywords: Case study. Furniture Industry. Diagnosis of Social Responsability 


\section{INTRODUÇÃO}

O modelo de desenvolvimento de nossa sociedade determina que as empresas busquem lucratividade permanente visa mas o crescimento econômico deve ser compatibilizado com as iniciativas de preservação ambiental ou manutenção do equilíbrio ecológico. O desenvolvimento sustentável é uma necessidade para atenuar os impactos do desenvolvimento econômico sobre o meio ambiente. Muitas organizações são exemplo no âmbito da sustentabilidade ambiental, porém, numa imensidão da demanda produtiva, ainda são muito poucas as organizações que possuem ações eficazes e sustentáveis de forma sistêmica.

A indústria moveleira se destaca no meio econômico, existindo incentivos para que o seu crescimento seja ainda maior. O crescimento da concorrência faz com que, muitas vezes, os aspectos ambientais fiquem em segundo plano. Neste setor, existe uma crescente geração de resíduos sólidos, ocorrência da falta de um estudo de ecodesign nos setores de engenharia de produto. Não menos importante, o setor utiliza-se de maquinários de grande, médio e pequeno porte, ocasionando um elevado consumo energético, muitas vezes, além do necessário.

O presente trabalho propõe um diagnóstico de ações de responsabilidade social dentro do escopo da sustentabilidade, em empresa moveleira do Vale do Caí.

A visão do modelo de desenvolvimento atual é clara e objetiva, visando a obtenção do lucro e do crescimento econômico. Com o aquecimento do setor produtivo o crescimento da utilização de recursos naturais torna nosso planeta insustentável, onde utilizamos mais recursos do que o mesmo consegue repor. Dentro desta visão, medidas de responsabilidade social sistemáticas que são adotadas pela organização, merecem destaque.

É notada uma mudança da exigência do mercado consumidor, onde a responsabilidade social e ambiental é também levada em consideração ao adquirir produtos ou serviços. A parcela pode ser ainda pequena, mas num mundo em que a troca de informações é cada vez mais rápida, esta nova cultura pode e deve expandir-se, trazendo uma melhor atenção das empresas no contexto ambiental. Para que se tenha uma visão exata da atual situação de uma empresa no âmbito da responsabilidade social, propõe-se a realização de um diagnóstico de responsabilidade ambiental em indústria moveleira do Vale do Caí, o que beneficiará não só a própria empresa, mas a qualidade de vida da população da região. Sua execução também servirá de referência para outras empresas moveleiras e de outros setores industriais.

\section{MATERIAIS E MÉTODOS}

As iniciativas sistematizadas para o atingimento de excelência na gestão de processos com relação a questões ambientais é definição de gerenciamento ambiental. (NAIME, 2004).

Entende-se como diagnóstico de responsabilidade social, uma ferramenta de gestão onde são inseridos procedimentos relativos a gerenciamento empresarial, com objetivo específico de levantamento de radiografia da empresa no âmbito social (NAIME, 2004). Segundo Moreira (2006) os objetivos principais de um diagnóstico consistem em analisar e evidenciar o contexto do gerenciamento ambiental da empresa relacionado ao modelo ISO ou SA, introduzindo noções sobre responsabilidade social, promovendo a percepção sobre o assunto e a necessidade de implementação de melhorias no gerenciamento de todas as ações. A autora também cita que um diagnóstico ambiental conscientiza os setores da empresa sobre seus papéis na melhoria do desempenho social e participativo dos colaboradores, identificando as oportunidades de melhoria.

A fim de proporcionar uma análise completa da empresa buscou-se em outras dissertações exemplos de questionários já realizados em outras empresas moveleiras, onde foi criado um questionário a ser utilizado nesta empresa estudada. Através deste questionário foi realizada uma pesquisa de campo, onde foram interrogados gerentes responsáveis pelas áreas estudadas em diferentes ocasiões.

A empresa não dispõe de mapeamento de processos, e o detalhamento dos principais deles precisou ser realizado por meio de questionamentos. Todos os setores da empresa foram analisados, desde o administrativo até a produção.

Grande parte das questões são administradas pela técnica de segurança do trabalho, juntamente com o gerente de produção e administrativo. Foi verificada com os setores de qualidade e gestão de 
pessoas a existência de projetos comunitários desenvolvidos pela empresa, a transparência e responsabilidade social.

\section{TRABALHOS ANTERIORES}

A contemporaneidade mundial demanda intensa produção de bens e serviços a fim de oferecer alimentação, vestimentas, repouso, educação à população. (CHIAVENATO, 2005). O consumo gerado pelas pessoas faz com que tenhamos uma transformação da economia. $\mathrm{O}$ acelerado processo de aquecimento mercadológico cria grande concorrência e movimentação na disputa por fatias de mercado. Davis et al (2001, p. 29) citam que as empresas devem superar-se em mais de uma dimensão competitiva, com objetivo de sobrevivência e também ampliação, diferente de regras anteriores existentes.

O modelo de desenvolvimento atual é insustentável, devendo afetar seriamente as próximas gerações. Não existe uma perspectiva intergeracional, ficando as futuras gerações sem poderem gozar de um meio ambiente equilibrado. Deve haver a idéia de uma sustentabilidade ambiental atual como solidariedade transgeracional, ou seja, pensando na futura geração, delimitando responsabilidades e obrigações do hoje para o amanhã. (PERALTA, 2011).

"O mundo contemporâneo requer uma contínua, intensa e incessante produção de bens e de serviços para que as pessoas possam se alimentar, vestir, repousar, educar-se, movimentar-se, viver [...]" (CHIAVENATO, 2005, p. 1). Sobre a rápida transformação da economia, Davis et al (2001, p. 29) citam que "os mercados, uma vez dominados por empresas locais ou nacionais são, agora vulneráveis à concorrência de empresas em todos os cantos do mundo." O autor complementa que "para sobreviver e prosperar em tal mercado global, as empresas devem superar-se em mais de uma dimensão competitiva, o que não era a regra anteriormente." Assumpção (2007) salienta que "a economia global no século XX deu um salto significativo, onde em 1900 o produto anual gerado somava apenas 2,4 trilhões de dólares e, em 1997, esta cifra teve um salto para 39 trilhões."

$\mathrm{O}$ aquecimento do setor produtivo e consequente crescimento econômico mundial levam, porém, a várias desvantagens. Moura (2003) destaca que a produção utiliza recursos naturais, gera efluentes e resíduos, a distribuição utiliza combustíveis poluentes, o consumo produz restos de produtos e embalagens que são descartados, gerando frequentemente impactos ambientais. Temos, então, a poluição ambiental crescendo paralelamente com o desenvolvimento econômico. Segundo Valle (1996) os efeitos mais sensíveis da poluição ambiental são a degradação da qualidade ambiental e prejuízos à saúde, segurança e qualidade de vida do homem, onde acabam afetando o meio ambiente. Segundo Assumpção (2007, p. 15), "o crescimento da economia global pode ser retratado na redução da biodiversidade. Na segunda metade do século XX, 11\%, ou seja, quase 9000 espécies da fauna e da flora também foram eliminadas".

Uma mudança de conceitos leva as empresas a pensarem no fator ambiental como solução e diferenciação. Segundo Reis (1996, p. 5) "várias empresas e diversos países identificaram nas questões ambientais um dos mais importantes fatores de sucesso para a continuidade da aceitação dos seus produtos e serviços nos mercados internos e externos." "A credibilidade ambiental é um importante fator de competitividade tanto nacional como internacional." (ROBLES JR.; BONELLI, 2006, p. 40). Esta mudança estratégica transforma, não só a empresa, mas toda a concorrência, tornando-se uma nova forma de pensar e agir organizacional. Porter (2002, p. 46) cita que "a evolução da indústria é importante estrategicamente porque a evolução, como é obvio, traz com ela mudanças nas fontes estruturais da concorrência".

Conforme Martins e Laugeni (2002) os japoneses, após a Segunda Guerra Mundial, desenvolveram novas estratégias empresariais com a procura incansável de melhorias na qualidade de seus produtos, buscando atender as necessidades dos consumidores. Moura (2003, p. 2) "existe uma velocidade muito grande de lançamento de novos produtos [...]." O autor salienta que "o consumidor está passando a valorizar mais a empresa fabricante e não apenas a marca do produto, estando assim ressaltado o comportamento ético da empresa, onde atuam diversos fatores, entre os quais o desempenho ambiental." Para Naime e Garcia (2004, p. 22) "o estudo da percepção ambiental é de fundamental importância para que possamos compreender melhor as inter-relações entre o homem e o ambiente, suas expectativas, satisfações e insatisfações, julgamentos e condutas." 
Os ecossistemas têm sido afetados pelas atividades humanas, sofrendo, no século XX, modificações impressionantes. As alterações consideráveis são a utilização de terras com florestas para cultivo, desvio de água doce, exploração da pesca além do normal, diminuição de áreas de mangue e arrecifes coralinos. Entre outras mudanças, surge o crescimento das emissões de dióxido de carbono, provocando o aumento da temperatura terrestre, erosão do solo e perdendo-se biodiversidade. (PERALTA, 2011), conforme afirmação:

ações e reações diante do mundo globalizado sugerem que se deve sair da zona de conforto em que se encontram as organizações, para encontrar novos modelos, novas tecnologias e novos parceiros na busca e melhoria das soluções em vez de usar a mesma mentalidade, esperando resultados diferentes, mas que não resolvem os mesmos desafios.

Desenvolvimento sustentável significa atender às necessidades da geração atual sem comprometer o direito das futuras gerações atenderem a suas próprias necessidades (VALLE, 1996). Kinlaw (1998, p. 11) complementa que "o desempenho sustentável [...] representa uma mudança fundamental nos valores e princípios que permeiam o ato de fazer negócios." Naime (2005) destaca que o diagnóstico ambiental serve como uma ferramenta de gestão ambiental, procedendo a uma radiografia da organização em vários aspectos de relacionamento com o meio ambiente, como tratamento de efluentes, gestão de resíduos e monitoramento e controle de emissões atmosféricas.

De acordo com a Rede de Cooperação para a Sustentabilidade - Catalisa (2003) pode-se definir Desenvolvimento Sustentável como modelo equilibrado de economia, política, social e ambiental, onde deve se satisfazer as necessidades de atuais gerações sem que sejam esquecidas as gerações futuras. Esta concepção se difunde juntamente com o questionamento do tipo de desenvolvimento adotado, constatando-se que o mesmo não é ecologicamente correto quanto aos recursos naturais utilizados, que ele propicia a geração de pobreza e grande desigualdade social, sendo politicamente injusto havendo concentração e abuso de poder, com alienação cultural quanto a seus próprios valores, não tendo ética no respeito aos direitos humanos e outras espécies.

Para a existência de sustentabilidade nas organizações o autor Kinlaw (1997) defende o Modelo de Gerenciamento de Desempenho Sustentável, onde são trabalhados conjuntos de marcos para o desempenho sustentável.

O marco número 1 - divulgação da política de desempenho sustentável - conforme Kinlaw (1997) tem o propósito de esclarecer de maneira exata o posicionamento da empresa em relação a meio ambiente e interesses comerciais, integrando sua preocupação com o meio ambiente a assuntos ligados a estratégias comerciais da empresa. Também focaliza a atenção da empresa em interesses fundamentais ao seu sucesso. Não pode haver dúvida sobre a valorização do meio ambiente pela empresa e a ligação do seu sucesso empresarial e o desempenho ambiental deve constar expressamente o conceito de sustentabilidade.

O estabelecimento de linhas de base do desempenho sustentável da empresa, como marco número 2 , representa o desempenho da organização em relação aos seus principais inputs e outputs do meio ambiente. Uma forma de controlar os inputs é medir os resíduos, poluentes e tóxicos oriundos dos fornecedores, a quantidade de resíduos decorrentes da transição entre processos, volume de água e energia utilizados. Os outputs incluem emissões de resíduos, emissões fugitivas, poluentes, resíduos não tratados, sucata de metais, papel e plástico. Podem ser, também, indiretos, gerados por embalagens e descarte, poluentes que resultam do uso pelo cliente. Os resíduos que são tratados e manipulados com utilização de produtos químicos, agentes biológicos, incineração, injeção em poços profundos ou aterros, ou até mesmo recuperados para reutilização também fazem parte deste controle. Deve haver manutenção de tudo que tange os processos de recuperação de resíduos e produtos secundários. (KINLAW, 1998).

O marco 3 é exemplificado pelo autor Kinlaw (1998) onde é afirmado que para haver êxito no desenvolvimento sustentável deve haver um programa de treinamento sobre o assunto, integrado ao programa geral de treinamentos da empresa, incluindo treinamento sobre novas tecnologias ambientais, proporcionando apoio e estímulo à criação do conhecimento e inovação. O autor salienta que o quarto marco determina que os projetos e objetivos de melhoria devem ser implementados, com a criação de projetos específicos que revejam todos os serviços e produtos, com vista a assegurar uma compatibi- 
lidade total com ecossistemas naturais. Exemplo disso temos em projetos de redução de embalagem, utilização de ciclos renováveis de processamento ou comercialização de resíduos.

O marco 5 afirma que a pesquisa e desenvolvimento de novas tecnologias devem possuir processos de apoio para que seja melhorado o desempenho ambiental da empresa. (KINLAW, 1998). Freitas apud Zottis et al (2009, p. 63) complementa que a "inovação é ação pragmática e aplicada do conhecimento no desenvolvimento e na transformação de produtos e processos, buscando elementos de diferenciação e aprimoramento com vistas ao desenvolvimento socioeconômico."

\section{RESULTADOS E DISCUSSÃO}

A empresa analisada não possui programas socioambientais com treinamentos e incentivos a melhoria da sustentabilidade e qualidade ambiental da organização e região. Porém, existem programas de grande mobilização para a melhoria da qualidade total, melhoria contínua e qualidade de vida dos colaboradores. É através desses programas que a empresa constrói e sustenta suas estratégias, práticas, políticas e modelos de gestão.

A melhoria na qualidade nos produtos, melhorias nos processos produtivos, diminuição de desperdícios e retrabalhos, diminuição de tempos de produção, melhoria da comunicação interna, são alguns dos benefícios dos seguintes programas:

- Integração de Pessoal

- Visitas Técnicas

- Pesquisa de Clima Organizacional

- Programa Treinar

- Programa 5S's

- Auditorias da Qualidade

- Grupos de Melhoria

- Programa Cultural

- Projeto Crescer

O programa de Integração de Pessoal é voltado para os colaboradores novatos e consiste num treinamento inicial sobre a história da empresa, sua visão, valores, princípios, programas de qualidade, normas e segurança do trabalho. Nesta etapa, os colaboradores recebem o Manual do Colaborador e Manual de Segurança, que possuem as orientações repassadas nesta integração.

É através deste programa que a empresa visa moldar o funcionário numa cultura de qualidade, mostrando deste o princípio a importância da melhoria contínua, sua relação com a qualidade e a satisfação do cliente.

Os colaboradores contratados são recebem este treinamento no primeiro dia de trabalho. Como são poucos os novatos, a empresa geralmente realiza este treinamento quando existe um número maior de participantes, ocorrendo geralmente uma vez ao mês.

No programa de Visitas Técnicas o principal objetivo é a busca por novas ideias através da visitação a empresas da região. Já ocorreram visitas a empresas de vários portes e segmentos, como Vinícola Salton, Vinícola Miolo, Via Marte e Todeschini.

As visitas técnicas são realizadas em grupo, como na figura abaixo, ou então por funcionários com objetivo mais específico. Não existe um calendário de realização das mesmas. É através delas que se amplia o conhecimento resultando em melhorias aplicadas na empresa.

A empresa também desenvolve pesquisa de clima organizacional, realizada anualmente existindo a participação de todos os colaboradores. O objetivo é medir a satisfação dos colaboradores em relação ao ambiente, qualidade de vida no trabalho, instalações, relacionamento com colegas e chefia. Depois de realizada a pesquisa de clima organizacional, os resultados são tabulados, onde são analisados pontos positivos e negativos, também levados a direção para buscar melhorias para a qualidade de vida na empresa.

O Programa Treinar consiste na realização de cursos em grupo ou específicos, existindo também incentivos a cursos técnicos externos. Os cursos em grupo são ministrados por professores 


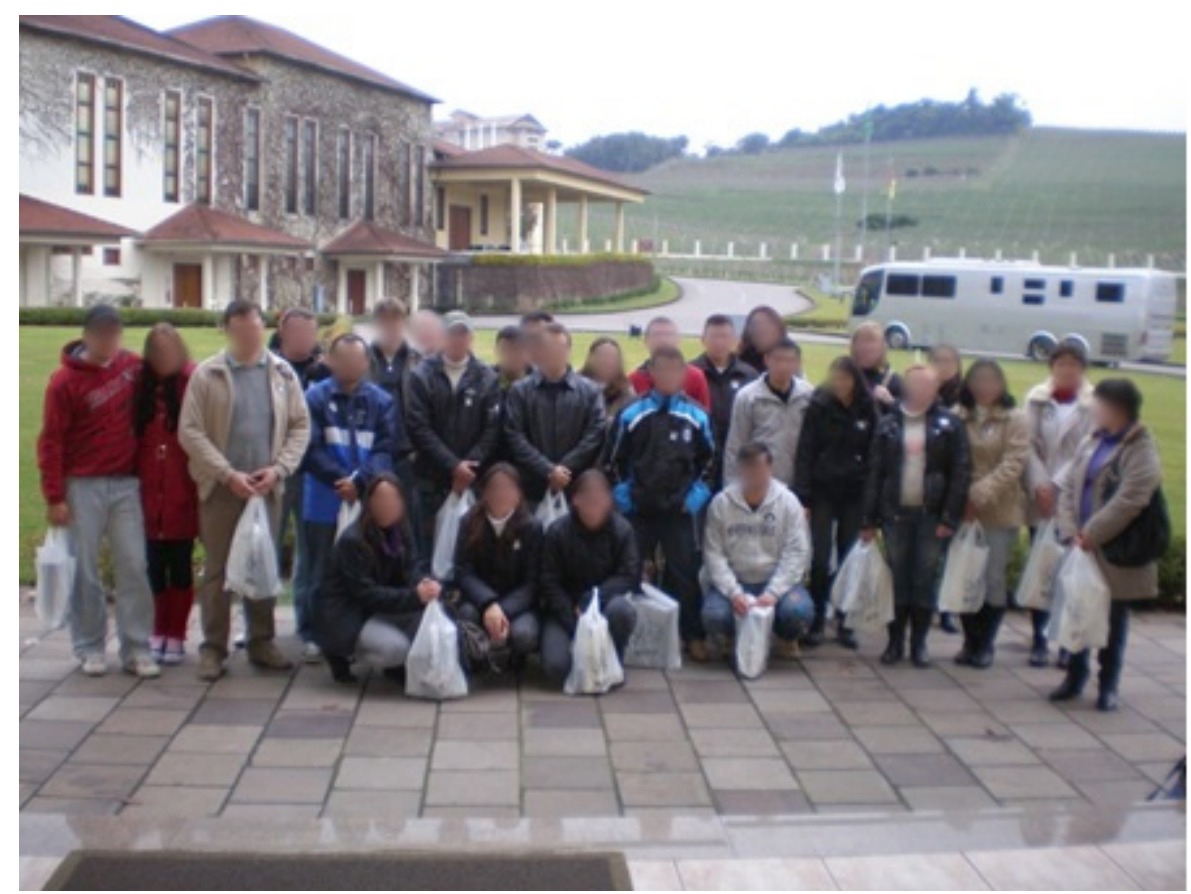

Figura 1: Programa Visitas Técnicas - Vinícola Salton Fonte: Dados dos Autores
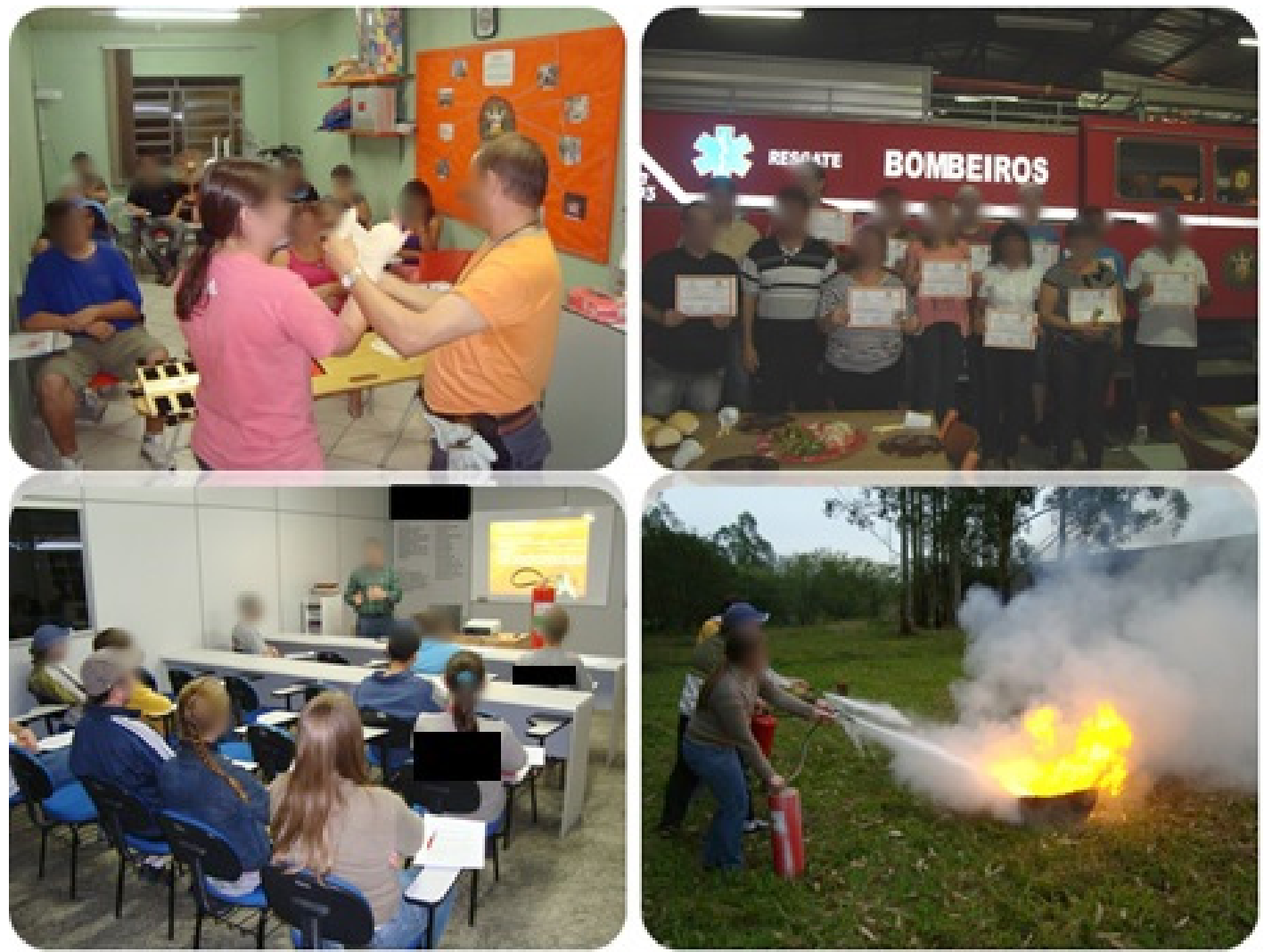

Figura 2: Programa Treinar

Fonte: Dados dos Autores

Nota: curso de primeiros socorros (acima); curso combate ao incêndio (abaixo) 
contratados e para os específicos existe um percentual de auxílio no custo total do curso.

O Programa 5S's implantado na empresa desde 2009 busca melhorar os 5 sensos, que são advindos de 5 palavras japonesas que começam por "S": Seiri (senso de utilização, seleção, descarte); Seiton (senso de organização, arrumação); Seiso (senso de limpeza); Seiketsu (senso de saúde, higiene e padronização); Shitsuke (senso de disciplina, autodisciplina).

O programa contou desde o início com o apoio da direção, e em 2009 houve o "Dia D", o dia da mudança de cultura da organização, juntamente com treinamentos e incentivo à toda equipe de trabalho. A empresa trabalha os cinco sensos desde então, visando melhorar a qualidade das informações, a qualidade de vida do trabalhador, com objetivos de fazer certo da primeira vez, diminuindo desperdícios, reduzindo custos e o índice de assistência técnica, melhorando a produtividade da empresa, a organização interna e os prazos de entregas, aumentando o índice de satisfação dos clientes.

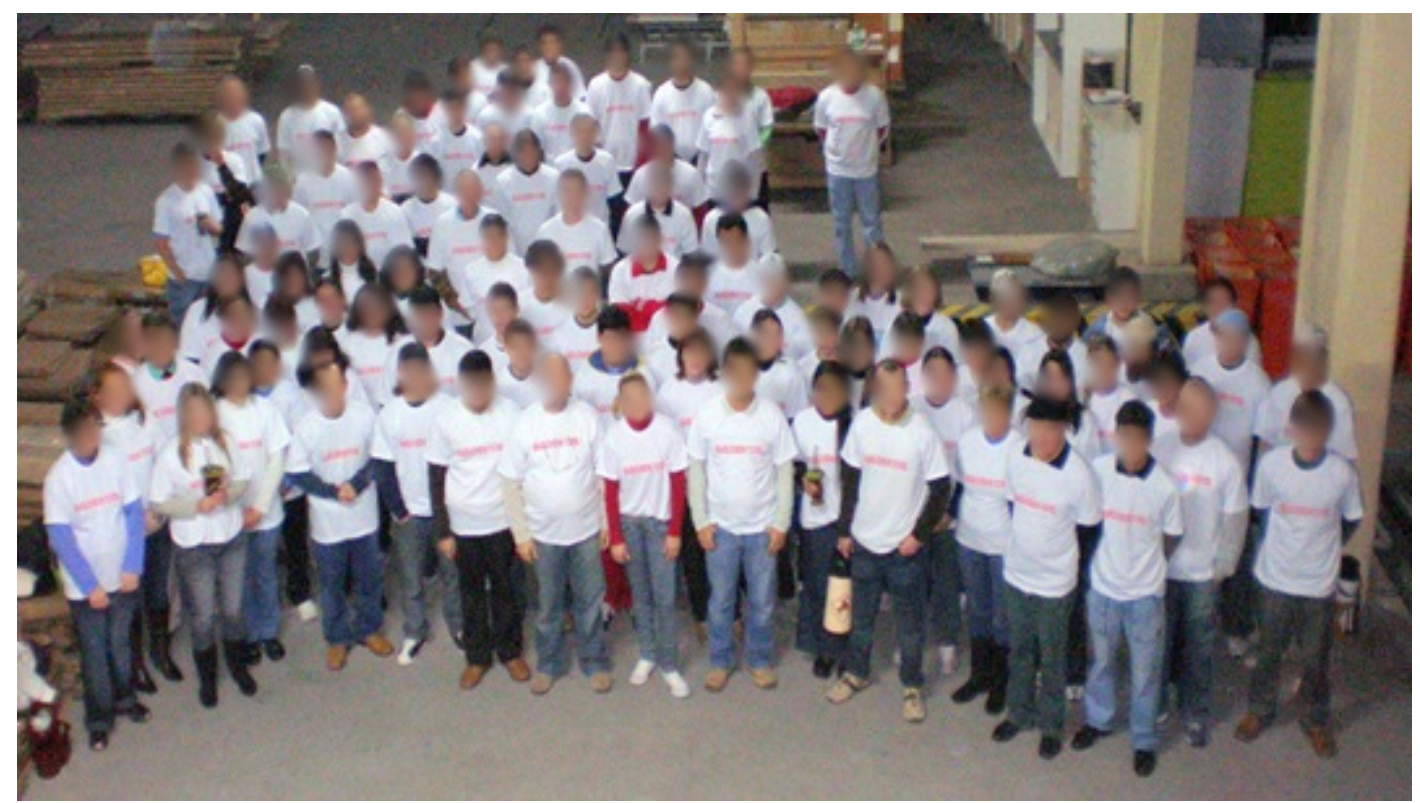

Figura 3: Dia D - o dia da limpeza e mudança cultural

Fonte: Dados dos Autores

Mensalmente são realizadas as Auditorias da Qualidade, onde todos os setores industriais e administrativos são vistoriados. O programa trabalha como apoio ao Programa 5S's, onde objetivo é melhorar a Organização, Arrumação, Limpeza, Padronização e Disciplina.

Através do programa de auditorias, a empresa fica dividida em 6 grupos e por meio de um calendário mensal os próprios funcionários realizam as auditorias internas, um grupo auditando o outro. As mesmas são realizadas utilizando questionário e máquina digital, onde são fotografadas as irregularidades encontradas.

Os resultados da auditoria são tabulados e é divulgada a pontuação final de cada grupo, que pode ser de 0 a 10 . O quadro das auditorias da qualidade também é atualizado por meio de sinalizadores coloridos, onde o grupo que ficar com nota maior do que 8,0 no senso recebe sinalização verde, notas entre 6,0 e 8,0 recebem sinalização amarela e por último, abaixo de 6,0, sinalização vermelha.

As auditorias da qualidade, além de desenvolverem a qualidade da organização, trazem benefícios para a qualidade de vida dos funcionários. Além disso, o programa conta com premiação trimestral, onde todos os funcionários do grupo com a melhor média de nota nos três meses do período recebem um rancho.

O programa Grupos de Melhoria utiliza a metodologia dos CCQ's (Círculos de Controle da Qualidade), onde os colaboradores trabalham na sugestão de idéias e implantação das mesmas em seus setores. Os setores são divididos em 4 grupos, onde cada um deles possui um número máximo de 7 funcionários que trabalham como facilitadores e se reúnem semanalmente para discutir os problemas e gerar soluções para os mesmos. 


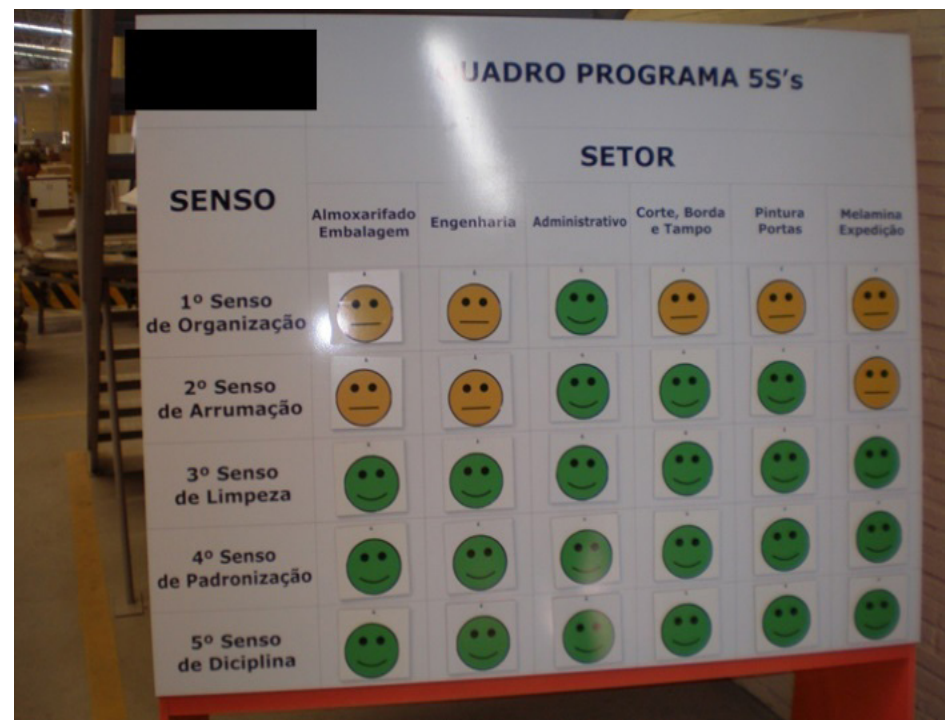

Figura 4: Quadro de auditorias da qualidade e programa 5s's

Fonte: Pesquisa de campo

Todos os meses são contabilizados os números de ideias implantadas nos setores e é escolhida a melhor ideia do mês, pelo grupo gestor do programa. As melhorias são divulgadas em quadro do programa, localizado na entrada da empresa. Os funcionários que não fazem parte das sete vagas de cada grupo também podem participar dando sugestões e auxiliando na implantação de melhorias, porém, não participam das reuniões semanais.

Os facilitadores do grupo que possuir a melhor ideia implantada do mês recebem como premiação um rancho. Se a melhor ideia implantada do mês for sugestão de um funcionário que não seja facilitador do grupo de melhoria, este também recebe um rancho como prêmio.

O programa Cultural visa melhorar a qualidade de vida do trabalhador e também o relacionamento interpessoal. São desenvolvidas atividades proporcionando diversão, arte, cultura, através de palestras, festivais e concursos. Este programa também tem objetivo de integrar a família dos colaboradores no contexto da empresa.

A indústria já desenvolveu atividades como excursões para um rafting em Três Coroas - RS, passeios ao Parque das Águas e Sítio da Família Lima. Além disso, foram desenvolvidas palestras de

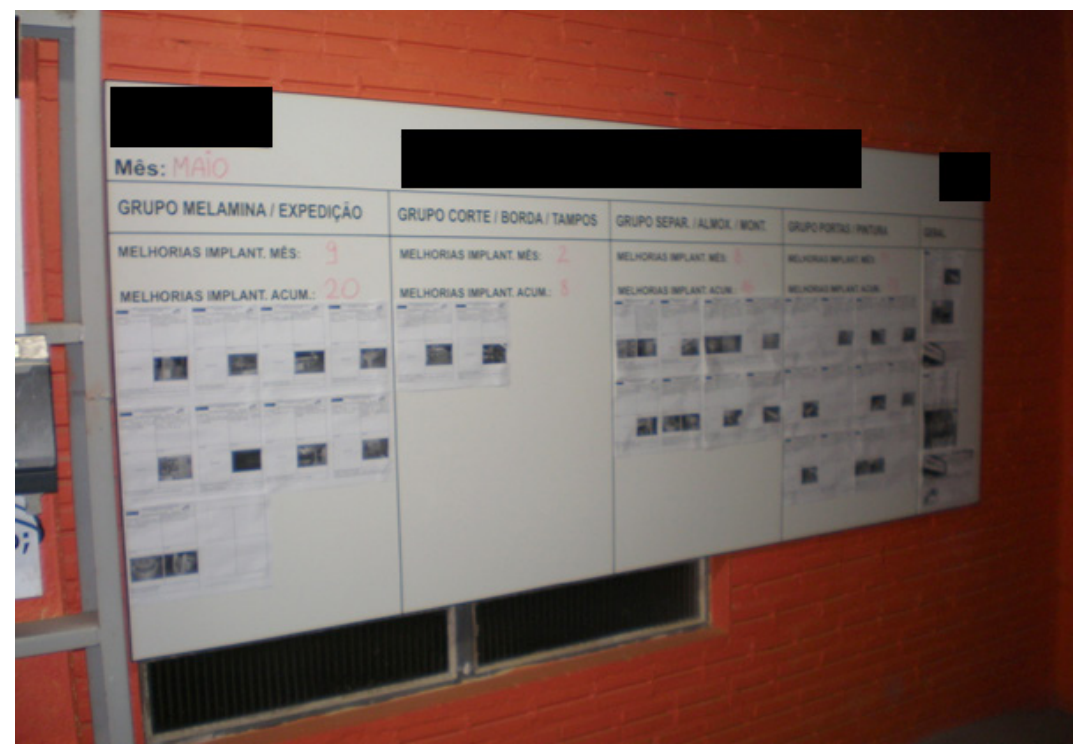

Figura 5: Quadro de divulgação dos grupos de melhorias

Fonte: Dados dos autores 


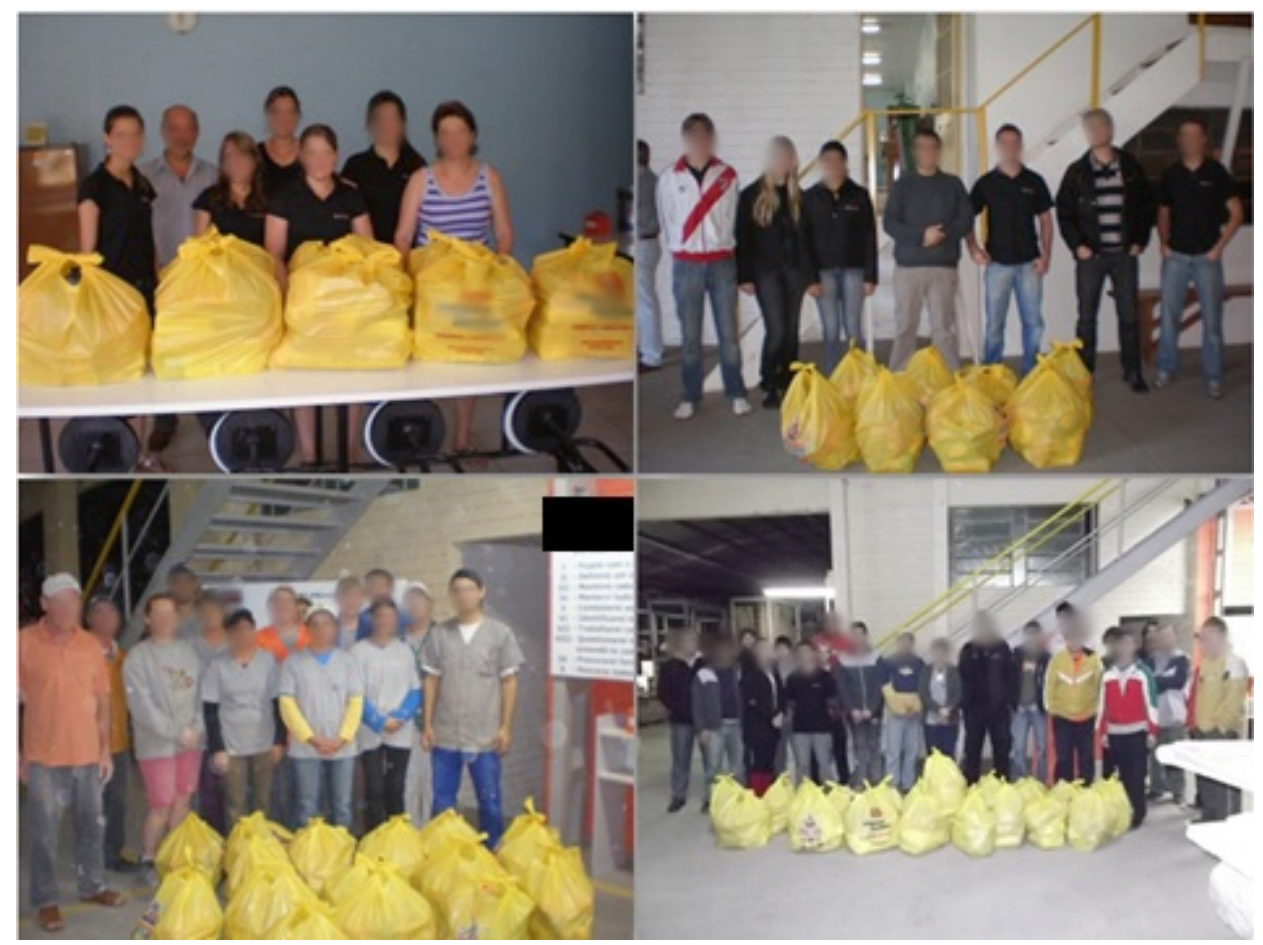

Figura 6: Premiação das auditorias da qualidade e grupos de melhoria

Fonte: Dados dos Autores

motivação, saúde e qualidade de vida, realização da SIPAT - Semana Interna de Prevenção de Acidentes de Trabalho, onde funcionários tiveram a oportunidade de participar e receber um diagnóstico de saúde, programa desenvolvido pelo Sesi.

Alguns outros atrativos do programa cultural são as gincanas, festivais de teatro, show de talentos e confraternizações de final-de-ano, que reúnem todos os funcionários numa grande família, para rirem e se divertirem. Anualmente também são realizados concursos de frases da qualidade, incentivando a busca pela melhoria contínua na organização.

A Kinderfest é um evento que teve início em 2012 para prestigiar os filhos dos funcionários.
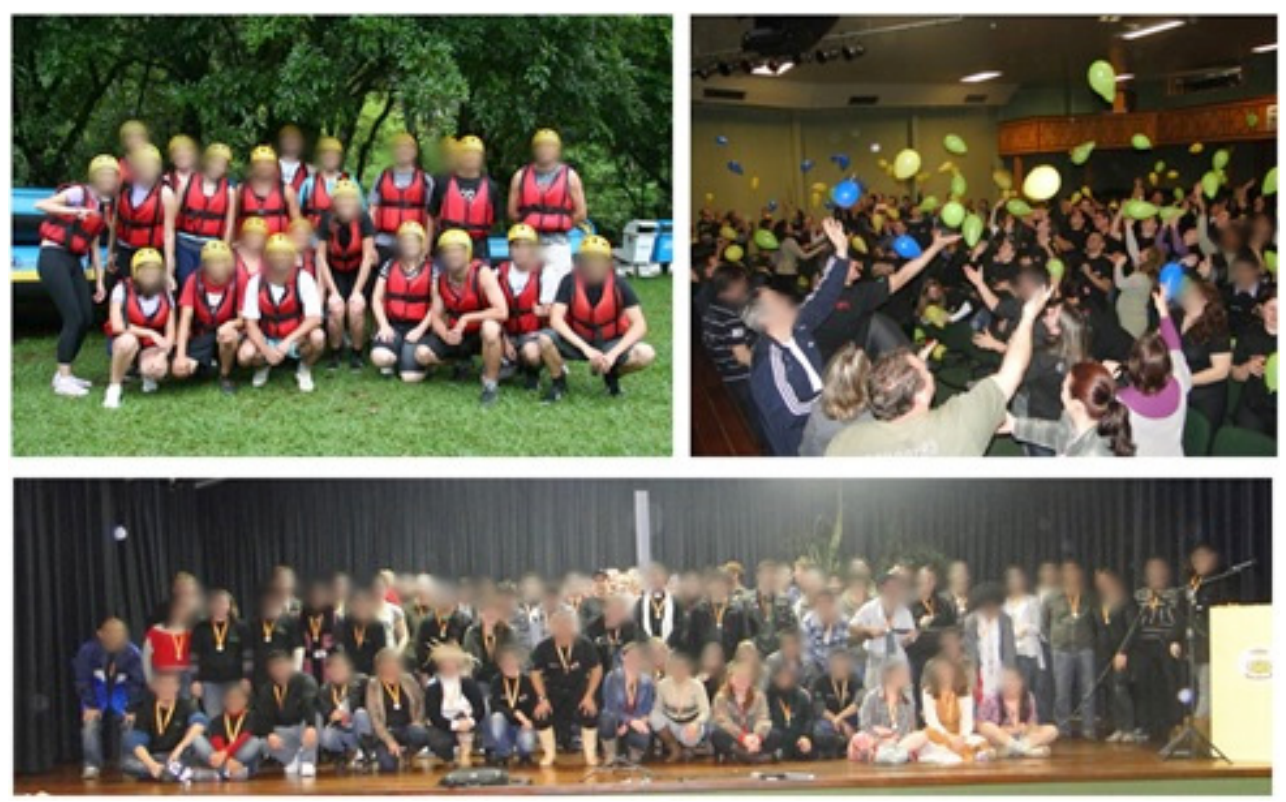

Figura 7: Programa Cultural

Fonte: Dados dos autores 
Um dia de muita festa e alegria, através de brincadeiras, futebol, videogame e brinquedos variados, trazendo também a oportunidade dos funcionários apresentarem a seus filhos os setores onde trabalham.

A criatividade dos filhos dos funcionários é incentivada através do Concurso de Cartões de Natal, onde os mesmos podem participar com desenhos com o tema Natal e a empresa. Os desenhos são divididos em três categorias por faixa etária. O melhor desenho de cada categoria é utilizado para a confecção do cartão de Natal da empresa, enviado para todos os clientes e parceiros.

Oportunizar a volta aos estudos no ensino fundamental e médio é o objetivo do Projeto Crescer. A empresa destina uma ajuda financeira de $50 \%$ do custo total do supletivo para os funcionários que sejam aprovados.

A empresa e seus funcionários trabalham também em iniciativas de ajuda à comunidade, onde já foram desenvolvidas campanhas de doações de alimentos, material escolar, livros e brinquedos a crianças de famílias carentes da região. Em 2012 aconteceu a campanha de doações para auxiliar com roupas e mantimentos o asilo Santo Expedito, onde reside o familiar de um dos funcionários. A empresa já desenvolveu campanha de doações de agasalhos com intuito de beneficiar famílias de baixa renda.

Mesmo não existindo nenhum treinamento e sensibilização a melhoria socioambiental, através dos grupos de melhoria a empresa passou a incentivar a devolução de pilhas e baterias. Por meio de uma parceria com empresa fornecedora de artigos de informática de cidade vizinha e que possui um posto de coleta em suas dependências, a empresa analisada também passou a ser uma alternativa como ponto de devolução de pilhas e baterias. A fornecedora parceira retira o material semanalmente.

A empresa estudada tem em sua cultura o incentivo à religião, onde diariamente, antes do início do turno de trabalho, é feita uma oração com a participação de todos os funcionários. A indústria é uma empresa familiar e sua direção é bastante engajada em causas sociais da região, auxiliando igrejas e escolas com mobiliário personalizado.

Através da lei de incentivo à cultura, a empresa também oferece auxílio a projetos culturais para o desenvolvimento da região, onde já houve ajuda financeira a grupos teatrais e à banda municipal, que incentiva a música a jovens da região.

\section{CONSIDERAÇÕES FINAIS}

$\mathrm{Na}$ fase de evolução do atual estágio civilizatório da humanidade, as empresas não podem mais se restringir a mera busca de lucro e satisfação do capital de seus investidores. Também são importantes a participação social que a empresa desenvolve, satisfazendo as expectativas de seus colaboradores e promovendo ações que beneficiem o conjunto da comunidade na qual a organização se encontra inserida.

Conforme demonstrado pelo presente trabalho, estas expectativas geradas e percebidas entre colaboradores e comunidade que integram como elementos fundamentais, as partes interessadas (stakeholders) são plenamente satisfeitos por ações sistematizadas e permanentemente revisadas buscando a melhoria continua da performance obtida, visando gerar as melhores condições possíveis de qualidade de vida para todas as partes envolvidas.

\section{REFERÊNCIAS}

ASSUMPÇÃO, Luiz Fernando Joly. Sistema de Gestão Ambiental: manual prático para implementação de SGA e Certificação ISO 14001/2004. 2 ed. Curitiba: Juruá, 2007.

CATALISA. 2003. Rede de Cooperação para a Sustentabilidade. Disponível em: www.catalisa.org.br. Acesso em 20/05/2012.

CHIAVENATO, Idalberto. Administração da Produção: uma abordagem introdutória. Rio de Janeiro: Elsevier, 2005.

DAVIS, Mark M.; AQUILANO, Nicholas J.; CHASE, Richard B. Fundamentos da Administração da Produção. Porto Alegre: Bookman, 2001. 
KINLAW, Dennis C. Empresa competitiva e ecológica: desempenho sustentado na era ambiental. São Paulo: Makron Books, 1998.

MARTINS, Petrônio Garcia; LAUGENI, Fernando Piero. Administração da Produção. São Paulo: Saraiva, 2002.

MOREIRA, Maria Suely. Estratégia e Implantação do Sistema de Gestão Ambiental (Modelo ISO 14000): Edição atualizada quanto a referências legais e à versão 2004 da NBR ISO 14001. 3 ed. Nova Lima: INDG Tecnologia e Serviços Ltda., 2006.

MOURA, Luiz Antônio Abdalla de. Economia ambiental: gestão de custos e investimentos. 2 ed. São Paulo: Juarez de Oliveira, 2003.

NAIME, Roberto Harb. Diagnóstico ambiental e sistemas de gestão ambiental: incluindo a atualização da série ISO 9000 e as novas NBR 14001/2004 e NBR ISO 19011/2002. Novo Hamburgo: Feevale, 2005.

NAIME, Roberto Harb; GARCIA, Ana Cristina de Almeida. Percepção ambiental e diretrizes para compreender a questão do meio ambiente. Novo Hamburgo: Feevale, 2004.

PERALTA, Carlos E. A justiça ecológica como novo paradigma da sociedade de risco contemporânea.

Revista Direito Ambiental e sociedade, v. 1, n. 1, jan./jun. 2011 (p. 251-271)

PORTER, Michel E. Estratégia Competitiva: Técnicas para Análise de Indústrias e da Concorrência. Rio de Janeiro: Campus, 2002.

REIS, Maurício J. L. ISO 14000: gerenciamento ambiental: um novo desafio para a sua competitividade. Rio de Janeiro: Qualitymark, 1996.

ROBLES JÚNIOR, Antônio; BONELLI, Valério Vitor. Gestão da qualidade e do meio ambiente: enfoque econômico, financeiro e patrimonial. São Paulo: Atlas, 2006.

VALLE, Cyro Eyer do. Como se preparar para as normas ISO 14000: qualidade ambiental; o desafio de ser competitivo protegendo o meio ambiente. 2 ed. São Paulo: Pioneira, 1996. 